\title{
Conformational Change Initiates Dehydration in Fluconazole Monohydrate
}

DOI:

10.1021/acs.cgd.0c00768

\section{Document Version}

Accepted author manuscript

Link to publication record in Manchester Research Explorer

\section{Citation for published version (APA):}

Basford, P. A., Cameron, C. A., \& Cruz-cabeza, A. J. (2020). Conformational Change Initiates Dehydration in Fluconazole Monohydrate. Crystal Growth \& Design. https://doi.org/10.1021/acs.cgd.0c00768

\section{Published in:}

Crystal Growth \& Design

\section{Citing this paper}

Please note that where the full-text provided on Manchester Research Explorer is the Author Accepted Manuscript or Proof version this may differ from the final Published version. If citing, it is advised that you check and use the publisher's definitive version.

\section{General rights}

Copyright and moral rights for the publications made accessible in the Research Explorer are retained by the authors and/or other copyright owners and it is a condition of accessing publications that users recognise and abide by the legal requirements associated with these rights.

\section{Takedown policy}

If you believe that this document breaches copyright please refer to the University of Manchester's Takedown Procedures [http://man.ac.uk/04Y6Bo] or contact uml.scholarlycommunications@manchester.ac.uk providing relevant details, so we can investigate your claim.

\section{OPEN ACCESS}




\title{
Conformational Change Initiates Dehydration in Fluconazole Monohydrate
}

\author{
Patricia A. Basford, ${ }^{a b^{*}}$ Christopher A. Cameron, ${ }^{c}$ and Aurora J. Cruz-Cabeza. ${ }^{b^{*}}$ \\ ${ }^{a}$ Medicinal Sciences, Pfizer R\&D UK Ltd, Sandwich, CT13 9NJ (UK) \\ ${ }^{\mathrm{b}}$ Department of Chemical Engineering and Analytical Science, University of Manchester, Manchester, M13 \\ 9PL (UK) \\ ${ }^{\mathrm{c}}$ Eurofins Professional Scientific Services, Clogherane, Dungarvan, County Waterford, Ireland, X35 T628 \\ *Corresponding authors.Emails: pat.basford@pfizer.com and aurora.cruzcabeza@manchester.ac.uk
}

\begin{abstract}
Experimental and computational techniques have been used in combination, to monitor the dehydration process of fluconazole monohydrate $(\mathrm{MH})$, this unveiling the dehydration mechanism at the molecular level. Experimentally, dehydration was observed to start at around $55^{\circ} \mathrm{C}$ and complete around $100^{\circ} \mathrm{C}$, with metastable $\mathrm{Pbca}, \mathrm{Z}^{\prime}=1$ polymorph (AH-C) as the sole product of dehydration (as determined by in-situ hot stage PXRD). Conformational and structural changes were identified as key in the initiation and progression of the dehydration process. Thermal expansion is most significant along the c-axis, with molecular dynamic (MD) simulations and experimental observations identifying that water migrates through the MH crystal lattice within the plane perpendicular to that direction. Water was found to migrate within the (001) plane along both the a and $\underline{b}$-axis directions. The MD simulations revealed that water was not able to migrate within the lattice at room temperature. Migration at $70^{\circ} \mathrm{C}(342 \mathrm{~K})$ was plausible, but only after the hydroxyl group undergoes conformational change. The conformational change, around the hydroxyl group, is key to both the weakening of the fluconazole-water hydrogen bonding, found in the $\mathrm{MH}$ structure, and the promotion of the fluconazole-fluconazole hydrogen bonding, required for the formation of polymorph AH-C.
\end{abstract}

\section{Introduction}

Organic molecules can crystallise in multiple forms such as polymorphs, hydrates or solvates. The term "solvate" is used when a solvent molecule becomes a constituent part of the crystal lattice. ${ }^{1-2}$ For the specific case where water is incorporated then the term "hydrate" is used. Due to water being ubiquitous in our atmosphere, and being a small molecule with an ability to form multi-directional hydrogen bonding, water is easily incorporated into a crystal structure, representing by far the most common type of solvate. ${ }^{3}$ A commonly adopted classification is to describe a hydrate as either an isolated site ("pocket") or channel hydrate. 4- $^{-}$ ${ }^{5}$ For isolated site hydrates the water is present within a lattice pocket, separated from direct 
interaction with the water molecules residing within an adjacent pocket. For channel hydrates water resides within a distinct channel running through the structure.

Approximately one in three pharmaceutical compounds form crystalline hydrates. ${ }^{6}$ Hydrates can be problematic to the pharmaceutical industry, with compounds exposed to multiple sources of water during product development and manufacture. Understanding the polymorph, solvate and hydrate landscape of the Active Pharmaceutical Ingredient (API) is particularly important, as changes in the crystal structure can impact the physicochemical properties of a material, so potentially influencing the manufacturability, compaction properties $^{7}$ and chemical stability, ${ }^{8-9}$ of the API or drug product. ${ }^{5,10}$ The formation of a hydrate, in general, lowers solubility ${ }^{11}$ therefore the conversion of the anhydrate to the hydrate, in the formulation or GI tract, could impact bioavailability. ${ }^{12}$ For nitrofurantoin this behaviour has been harnessed to provide an extended release formulation (MacroBID ${ }^{\circledR}$ ) for this important antibiotic, reducing the dosing regimen. MacroBID contains both monohydrate $(75 \% \mathrm{w} / \mathrm{w})$ and anhydrous nitrofurantoin $(25 \% \mathrm{w} / \mathrm{w})$. Conversion of the anhydrous component to the hydrate within the GI tract slows the dissolution rate and therefore absorption of the drug (label claim).

The hydration state of a material is influenced by temperature, pressure and water activity, therefore any process that influences these, has the potential to impact the hydration state. API isolation, milling and micronization processes all subject the API to a dry nitrogen purge gas, used to provide an inert atmosphere, so mitigating the risk of explosion. Subjecting a hydrate to such a process would result in some level of dehydration, unless the hydrate had a very high level of kinetic stability. In addition, processes such as wet granulation and lyophilisation subject a material to an aqueous rich environment followed by drying, this potentially resulting in variable solid form output. Wet granulation was found to change chlorpromazine hydrochloride ${ }^{13}$ and carbamazepine ${ }^{14}$ from one anhydrous form to another, the mechanism for this form conversion was identified to be via an intermediate hydrated state, only present during the wet granulation stage. During the lyophilisation of pentamidine isethionate (PI), both the freezing rate and the solution concentration were found to influence the anhydrous form present in the final product. ${ }^{15} \mathrm{PI}$, can form a trihydrate, Form B is only accessed through dehydration of this trihydrate form. Applying slow cool rates to high concentration solutions allowed for partial formation of the trihydrate during processing. As a result, a mixed Form A and B product was produced.

Dehydration behaviour can be classified into three main types: ${ }^{16}$ i) the anhydrous and hydrate forms are isostructural, with water diffusion through lattice pores and channels; ${ }^{17}$ ii) a new crystal lattice is formed upon dehydration giving rise to either a polycrystalline material within the original particle, ${ }^{18}$ growth from the surface, ${ }^{19}$ particle disintegration or cracking $;{ }^{20}$ iii) dehydration results in a poorly crystalline or an amorphous form, which may then crystallise. ${ }^{17,21}$ Many of the hydrates studied in the literature are channel structures ${ }^{18,22-25}$ which exhibit type i behaviour, with the dehydration process being completely reversible. ${ }^{26-32}$ Because of the significant structural changes involved, the dehydration behaviour of pocket hydrates ${ }^{4}$ is more complex, following type ii) and iii) behaviour, and thus has been studied to a much lesser extent. ${ }^{33-34}$ 
In this context, gaining a better understanding of hydration and dehydration mechanisms in molecular solids would allow for better control during the processing of these materials. In a previous contribution, we studied the differing hydration kinetics of fluconazole polymorphs $^{35}$ whilst in this contribution we study the dehydration kinetics of the monohydrate, and the molecular mechanisms driving this process. Fluconazole [2-(2,4difluorophenyl)-1,3-bis (1H-1,2,4-triazol-1-yl)-propan-2-ol] is a flexible drug compound (Figure 1) used in the systemic treatment of fungal infections. Multiple polymorphic forms of fluconazole have been reported in the literature, ${ }^{36-41}$ as well as various solvates ${ }^{42}$ and a monohydrate. ${ }^{43}$ Fluconazole monohydrate $(\mathrm{MH})$ falls into the class of hydrates termed as a pocket hydrate, ${ }^{4}$ and therefore some level of structural change is required for dehydration to occur.

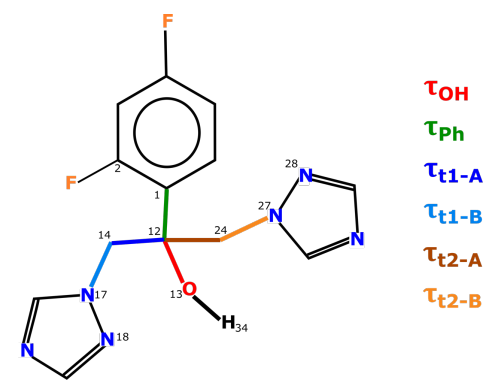

Figure 1 Structure of fluconazole with atom numbering and a definition of its six rotatable bonds. ${ }^{35}$ Partial atomic numbering provided to define the torsion angles $\left(\tau_{\mathrm{OH}}=34-13-12-1\right)$.

The monohydrate $(\mathrm{MH})$ crystallises in the triclinic $P \mathrm{I}$ space group with one fluconazole molecule in the asymmetric unit. These molecules hydrogen bond via two water molecules to form an extended hydrogen bonded dimer $R_{4}^{4}(18) \cdot{ }^{44}$ Dimers form an infinite hydrogen bonded chain, $\mathrm{C}(12)$, connecting adjacent fluconazole molecules via water fluconazole hydrogen bonding. The water is found in environment $5,{ }^{45}$ bonded with three strong hydrogen bonds, donating twice and accepting once (Figure 2).

\section{Deleted: Figure 1}

Deleted: . e.g.,

Formatted: Highlight

Formatted: Highlight 

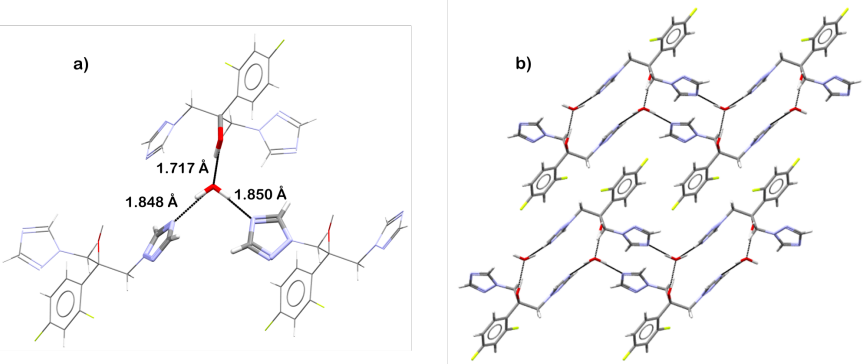

Figure 2 Fluconazole monohydrate hydrogen bonding a) motif, including hydrogen bond lengths and b) network (viewed down the b-axis). CSD refcode IVUQIZ. ${ }^{42}$

\section{Methods}

\subsection{Materials}

Fluconazole was gifted by Pfizer Global Supply, Ringaskiddy, Ireland. Firstly, a small scale $(600 \mathrm{mg})$ seed batch of the monohydrate $(\mathrm{MH})$ was produced, this then being used in the crystallisation of a larger, seeded batch $(9 \mathrm{~g})$. For the synthesis of the seed: Fluconazole (200 $\mathrm{mg} / \mathrm{mL})$ was dissolved in ethanol: water $(3: 1 \mathrm{v} / \mathrm{v})$ at $70{ }^{\circ} \mathrm{C}$ and the solution was then cooled to $10{ }^{\circ} \mathrm{C}$ at $2{ }^{\circ} \mathrm{C} / \mathrm{min}$. For the larger scale batch, fluconazole $(200 \mathrm{mg} / \mathrm{mL})$ was dissolved in ethanol: water $(1: 1 \mathrm{v} / \mathrm{v})$ at $70{ }^{\circ} \mathrm{C}$, the solution was cooled to $50{ }^{\circ} \mathrm{C}$ at $1{ }^{\circ} \mathrm{C} / \mathrm{min}$ and seeded with $\mathrm{MH}(1 \% \mathrm{w} / \mathrm{w})$; cooling then continued at $5{ }^{\circ} \mathrm{C} / \mathrm{min}$ to $20^{\circ} \mathrm{C}$. The resultant powder was isolated (filtration) and dried under ambient conditions for 1 week, i.e., not subject to heat or low humidity. The seed, and larger scale batch were confirmed to be phase pure through comparison with the simulated powder X-ray diffraction pattern of the MH (see section 2 of the Supporting Information).

\subsection{Thermal analysis}

Differential Scanning Calorimetry (DSC) was performed with a TA Instruments Discovery DSC (heat-flux system). A sample $\left(2 \mathrm{mg}\right.$ ) was heated from 20 to $200^{\circ} \mathrm{C}$, in an aluminium $\mathrm{T} 0$ sample pan (crimped lid), at a rate of $10^{\circ} \mathrm{C} / \mathrm{min}$.

The dehydration behaviour of the monohydrate was assessed using thermogravimetric analysis (TGA) using a TA Instruments Discovery TGA, with an auto-sampler. Samples (8 $\mathrm{mg}$ ) were sealed inside a vented (two pre-drilled $0.1 \mathrm{~mm}$ diameter holes) aluminium sample pan. This pan selection allowing for a reproducible sample presentation whilst limiting the sample contact with the dry equipment purge gas. For calculation of the activation energy, data sets were acquired isothermally at $5{ }^{\circ} \mathrm{C}$ intervals across the temperature range 50 to 70 ${ }^{\circ} \mathrm{C}$. The run time was automated using an "abort weight" setting of $<94.5 \%$, this representing a dehydration of $97 \%$. (Full dehydration was taken as a weight loss equivalent to 
one mole of water; $5.56 \%$ w/w.) Replicate tests were performed at each temperature. A sample was also heated at $10{ }^{\circ} \mathrm{C} / \mathrm{min}$ to $200^{\circ} \mathrm{C}$ to provide complimentary data to the DSC analysis. Data was collected and analysis performed using TA Instruments TRIOS software. ${ }^{46}$

\subsection{Hot stage microscopy}

Hot stage microscopy (HSM) was performed using a Linkam T96-S controller connected to a Linkam THMS600 stage. The stage was placed on a Nikon LV100 polarising light microscope, fitted with a range of objective lenses and a camera. The dehydration behaviour of the MH was observed with crystals immersed in a drop of silicone oil (325 cSt). Samples were heated at $20{ }^{\circ} \mathrm{C} / \mathrm{min}$. The hot stage was controlled and images captured (1 per second) using Linkam Scientific LINK software v1.0.5.8. ${ }^{47}$

\subsection{Hot stage PXRD}

The fluconazole $\mathrm{MH}$ dehydration product was confirmed using hot stage powder X-ray diffraction. A Bruker AXS Ltd., D8 Discover, powder X-ray diffractometer fitted with an environmental stage, a theta-theta goniometer and a LynxEye XE detector was used. Samples were presented for analysis as a thin layer on a zero background silicon wafer sample mount. An initial analysis was performed at $25{ }^{\circ} \mathrm{C}$ prior to heating. Data sets were collected at 30 , 40,60 and $80{ }^{\circ} \mathrm{C}$, finally cooling the sample for analysis at $25^{\circ} \mathrm{C}$. The sample was held at temperature for a period of 20 min prior to collecting the powder pattern. The sample was irradiated with copper K $\alpha$ X-rays (wavelength $=1.5406 \AA$ ) with the X-ray tube operated at $40 \mathrm{kV} / 40 \mathrm{~mA}$. The analysis was performed with the goniometer running in continuous mode from $2-40^{\circ} 2 \theta$, step size $0.018^{\circ} 2 \theta$, step time 0.20 seconds. Data was collected using DIFRAC Measurement Centre v7.5.05 and analysed using Bruker AXS DIFFRAC.Suite EVA.v5.0.0.22.48

\subsection{Face Identification}

A combination of data acquired using single crystal and powder X-ray diffraction techniques was used to identify the faces found on the surface of the fluconazole crystals studied here. A single crystal of fluconazole monohydrate was grown using an evaporative method and the structure of this crystal solved (see section 3 of the Supporting Information). The crystal was indexed using CrysAlisPro software. ${ }^{49}$ Faces were assigned using a series of images taken of the crystal as it was rotated. The dominant face was found to be the (010) face with the a-axis running along the length of the crystal (Figure 3 ). 

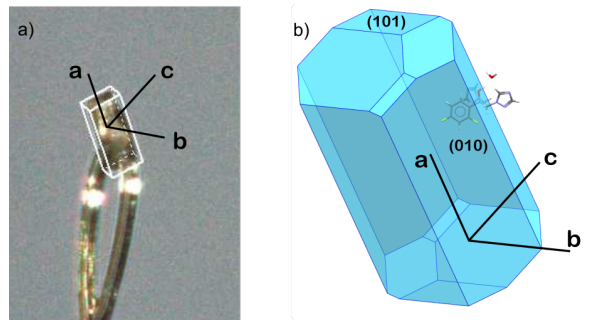

Figure 3 Axis and face assignment for fluconazole monohydrate a) single crystal compared to b) BFDH morphology (calculated using Mercury).

Fluconazole monohydrate has a preference to grow as rods and elongated plates, and so the powder X-ray diffraction pattern, for samples prepared on a zero background, cut $\mathrm{Si}$, specimen mount, is subject to preferred orientation. This behaviour was used to identify the dominant faces on the fluconazole crystals studied here. From a comparison of the peak height for each reflection found in capillary and zero background powder X-ray diffraction patterns, the preferred orientation was identified. The relative peak intensities found for the capillary data were in good agreement to the pattern simulated from the single crystal structure. For the zero background preparation peak intensities for the $\{001\},\{100\},\{101\}$, $\{111\}$ and $\{110\}$ planes were significantly lower than found in the capillary data, indicating that these faces lie perpendicular to the background. The peak intensity for the $\{010\}$ and $\{011\}$ planes were greater than found for the capillary data, indicating that these faces sit parallel to the background and will be dominant on the surface (see section 4 of the Supporting Information).

\subsection{Calculation of Activation Energy; Isoconversional Method}

Kinetics relates to the rate of a process and is dependent on environmental parameters, for example, dehydration could be expected as a result of exposing a hydrate to a dry atmosphere, increased temperature $(\mathrm{T})$, reduced pressure $(\mathrm{P})$ or a combination of these. Rate is defined as in equation 1, with $\mathrm{h}(\mathrm{P})$ only being relevant if a pressure change occurs during the process. The dependence of a process on temperature is represented by the rate constant $\mathrm{k}(\mathrm{T})$ and the dependence on the extent of conversion ( $\alpha$ ) (range 0 to 1 ) is represented by a kinetic reaction model $(f(\alpha))$. The Arrhenius equation (2) is used to describe the temperature dependence of reaction rates. $\mathrm{A}$ is the pre-exponential factor, $\mathrm{E}_{\mathrm{a}}$ the activation energy and $\mathrm{R}$ the Gas Constant $\left(8.314 \mathrm{~J} \mathrm{~K}^{-1} \mathrm{~mol}^{-1}\right)$

$$
\begin{gathered}
\left.\frac{d \alpha}{d t}=k_{(} T^{\prime} f_{(} \alpha\right)^{h}(P) \\
k_{(} T_{)}=A e^{\left(\frac{-E a}{R T}\right)}
\end{gathered}
$$


Taking the logarithmic derivative of the reaction rate (equation 1), for a reaction at a constant pressure, gives equation 3 . At any given constant value of $\alpha$, then $\mathrm{f}(\alpha)$ is also a constant, therefore the final term in equation 3 equates to zero. Combining equations 2 and 3 provides equation 4.

$$
\begin{gathered}
{\left[\left(\frac{d \ln (d \alpha / d t)}{d T^{-1}}\right)\right]_{\alpha}=\left[\left(\frac{d \ln k(T)}{d T^{-1}}\right)\right]_{\alpha}+\left[\left(\frac{d \ln f(\alpha)}{\left.d T^{-1}\right)}\right]_{\alpha}\right.} \\
\frac{d \ln (d \alpha / d t)}{d T^{-1}}=-\frac{E_{\alpha}}{R}
\end{gathered}
$$

The activation energies $\left(E_{a}\right)$ for the dehydration of the MH was calculated using a "modelfree" isoconversional approach. ${ }^{50}$ This is based on the principal that the reaction rate, at a defined conversion fraction $(\alpha)$, is only a function of the temperature (at constant pressure). The activation energy is calculated using the rates, at defined $\alpha$, from a series of measurements conducted at differing temperature $\left(E_{\alpha}\right)$, therefore, the dependence of $E_{a}$ on $\alpha$ is established. A significant variation of $\mathrm{E}_{\alpha}$ may indicate that a kinetically complex process is in play, such that a single model would not be applicable throughout the conversion. The isoconversional method applied here is that of Friedman ${ }^{51}$ and can be applied to any temperature program based on equation 4 .

Dehydration rates across a conversion fraction range of $0.1-0.9$ were taken at 0.1 intervals through linear regression analysis of portions of the data set, the sampled region was highly dependent of both the extent of conversion and the temperature, but in general between 1 and 5 minutes of data were considered at each conversion fraction (see section 5 of the Supporting Information).

The rate data was compiled into an Arrhenius plot, the slope for the data and 95\% confidence intervals at each conversion fraction were calculated using full regression analysis. The derived rate data was used to calculate the activation energy values for each conversion fraction (equation 4) and the confidence intervals applied to calculate the upper and lower limits for the activation energy error.

\subsection{Molecular Dynamics Method}

Molecular Dynamics were carried out using the Forcite Module as implemented in Materials Studio. The low temperature (100K) crystal structure of fluconazole monohydrate (MH) was retrieved from the CSD (IVUQIZ02). The COMPASS-II (with its own charges) forcefield was chosen for all simulations since it was specifically designed to be generally suitable for application to condensed phases ${ }_{x \rightarrow}^{52}$ and has been shown to be one of the best off-the shelf forcefields for the simulation of molecular crystals $53-54,55,56$ A number of other forcefield models available in Materials Studio were also tested but COMPASS and COMPASS-II provided the best results (ESI),
Deleted: 3

Formatted: Check spelling and grammar

Deleted: 3

Formatted: Check spelling and grammar

Formatted: Check spelling and grammar

Deleted: 3

Formatted: Highlight

Deleted: The crystal structure was then geometry optimised, allowing the unit cell parameters to relax....

Deleted: was the

Deleted: model use for these simulations. The COMPASS forcefield wassi

Deleted: .

Formatted: Highlight

Formatted: Highlight

Deleted: The forcefield was extensively validated

Formatted: Superscript, Highlight

Deleted: The COMPASS II forcefield extends the coverage for use with polymers and pharmaceutical like molecules adding functional groups commonly found in data bases for these molecules, with particular attention being given to the parameterisation of nitrogen, sulfate and sulfonate groups.

Formatted: Superscript, Highlight

Formatted: Superscript, Highlight Deleted: The application of forcefields to lattice energy calculations for crystal
structures of pharmaceutically relevant molecules has been conducted, with COMPASS II being ranked as the recommended forcefield for such molecules....

Formatted: Superscript, Highlight

Formatted: Superscript, Highlight

Formatted: Highlight

Deleted: readily

Deleted: were applied

Deleted: , with the optimised structures of the MH then compared with the non-optimised structure using the COMPACK algorithm (as implemented in Materials

Mercury), the $\operatorname{rmsd}_{20}$ values have been tabulated in section 6

of the supporting informationresults (ESI)..

Deleted: 
Next, a 4 x 2 x 2 supercell was generated. This results in a periodic cell of $22.3 \AA$ x $23.3 \AA$ x $24.3 \AA$ containing 64 molecules in total ( 32 fluconazole and 32 water molecules, Figure 4 ). Molecular dynamic simulations were carried out at six different temperatures $(100 \mathrm{~K}, 200 \mathrm{~K}$, 249K, 298K, 347K, 396K). The procedure applied for each temperature was the following: a) the system was equilibrated for $50 \mathrm{ps}$ in the NVT ensemble, b) this was followed by a $50 \mathrm{ps}$ equilibration in the NPT ensemble and c) a production run of $500 \mathrm{ps}$ in the NPT ensemble. The initial structure for step a) was taken from the equilibrated simulation at the previous temperature (i.e. for the simulation at $249 \mathrm{~K}$, the equilibrated cell at $200 \mathrm{~K}$ from step c) was taken as the starting point).

A time step of $1 \mathrm{fs}$ was used in all simulations. For the NVT simulations the Nose thermostat was used whilst for the NPT the Nose thermostat in combination with the Berendsen barostat were applied. Electrostatic non-bonded terms were evaluated using the Ewald summation, whilst a cut-off of $9.5 \AA$ was used for the evaluation of the van der Waal terms. For $298 \mathrm{~K}$ and $347 \mathrm{~K}$, an additional production run of $10 \mathrm{~ns}$ in the NPT ensemble was produced. Derivation of average system properties was done for the production runs only. Diffusion coefficients for water were derived by calculating the slope of the mean squared displacements (MSD) as a function of the simulation time and applying the Einstein relation where $\mathrm{D}=(\mathrm{MSD}) / 6 \Delta \mathrm{t}$.

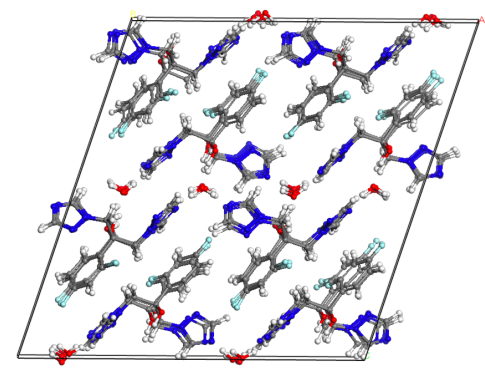

Figure 4 Simulation box for the fluconazole MH containing 32 water molecules and 32 fluconazole molecules.

\section{Results}

\subsection{Characterisation of dehydration upon heating}

The monohydrate dehydration process was monitored using a number of thermal characterisation techniques: DSC, TGA, hot stage pXRD and HSM.

Dehydration of the monohydrate occurs on heating. The first endotherm seen in the DSC thermogram corresponds to the dehydration of the monohydrate, with a threshold temperature of $60{ }^{\circ} \mathrm{C}(333 \mathrm{~K})$, the event completing just above $100{ }^{\circ} \mathrm{C}$. In the TGA thermogram a single weight loss event is observed across the same temperature range (Figure 5), this equating to a loss of one mole of water (Fluconazole MH MW = 324.3). This is in line with the water being present in a single environment, environment $5 .{ }^{45}$
Deleted: Figure 4

Deleted: Figure 5 
The dehydration endotherm is initially broad followed by a sharper event with a peak maximum at $101.8^{\circ} \mathrm{C}$. This may not necessarily imply that fluconazole dehydration occurs as a twofold event, the dehydration behaviour may have changed on exceeding the peritectic dissociation temperature of the hydrate. Characterisation using a vented sample pan and a slower heating rate $\left(5^{\circ} \mathrm{C} / \mathrm{min}\right)$ virtually eliminates the presence of this sharp event however the enthalpy of the endotherm remaining the same (see ESI). The enthalpy of dehydration $\left(\Delta \mathrm{H}_{\mathrm{d}} ; 159.3 \mathrm{~J} / \mathrm{g}\right)$ can be related to the specific enthalpy of sublimation of ice $\left(\Delta \mathrm{H}_{\mathrm{s}} ; 2830 \mathrm{~J} / \mathrm{g}\right.$ of water); the molar loss of water can be calculated according to equation $5 .{ }^{57}\left(\mathrm{MW}_{\mathrm{s}}\right.$ fluconazole anhydrate $=306.3 \mathrm{~g} / \mathrm{mol}$ and water $\left.\mathrm{MW}_{\mathrm{w}}=18.0 \mathrm{~g} / \mathrm{mol}\right)$. The enthalpy of dehydration equates to the loss of one mole of water, in line with the TGA data.

$$
n=\frac{\Delta H_{d} \times M W_{s}}{\left(\Delta H_{s}-\Delta H_{d}\right) \times M W_{w}}
$$

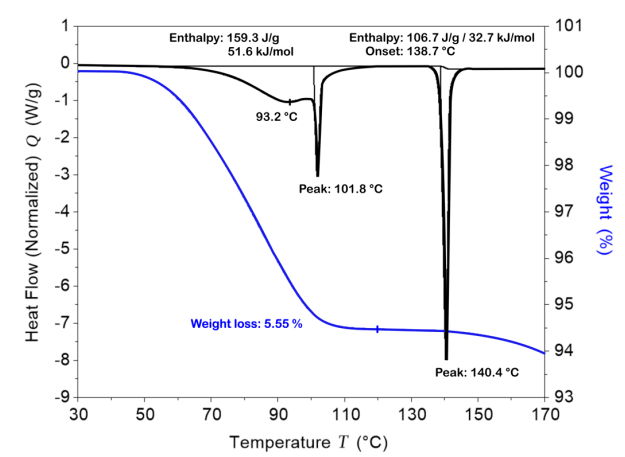

Figure 5 Overlay of DSC (black) and TGA (blue) thermograms for fluconazole monohydrate, obtained at a heating rate of $10{ }^{\circ} \mathrm{C} / \mathrm{min}$. Melting point at $140{ }^{\circ} \mathrm{C}$ is consistent with a melt of anhydrous polymorph AH-C.

As the temperature is increased, hot stage powder XRD data shows a direct conversion of the MH into the Pbca, $Z^{\prime}=1$ polymorph, CSD refcode IVUQOF02, described in our previous paper as $\mathrm{AH}-\mathrm{C}^{35}$ (Figure 6 ). At $60^{\circ} \mathrm{C}(333 \mathrm{~K}$ ) peaks representative of both the $\mathrm{MH}$ and $\mathrm{AH}-\mathrm{C}$ forms are present, with no evidence for intermediate forms. At $80^{\circ} \mathrm{C}$ only peaks for AH-C were identified. The temperature for the dehydration process is in line with the datasets collected using both DSC and TGA, with dehydration completing at a lower temperature due to holding the samples at temperature $(20 \mathrm{~min})$ prior to pXRD analysis. The dehydration product, on holding a $\mathrm{MH}$ sample at $0 \% \mathrm{RH}$ and $30^{\circ} \mathrm{C}$, was also found to be $\mathrm{AH}-\mathrm{C}$ (see section 8 of the Supporting Information) confirming $\mathrm{AH}-\mathrm{C}$ as the dehydration product regardless of the mechanism applied to remove the water.
Formatted: Highlight

Deleted: section 7 of the Supporting Information 


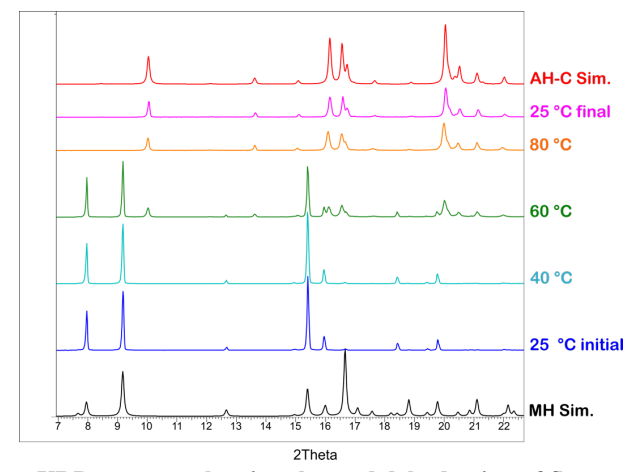

Figure 6 Hot Stage pXRD patterns showing thermal dehydration of fluconazole monohydrate. Experimental patterns overlaid with MH (293K) and AH-C (293K) $)^{35}$ simulated patterns.

Hot Stage Microscopy: On heating fluconazole monohydrate within oil (Figure 7), crystals were observed to grow off the surface of the visible, (011) and (010) crystal faces. This was first observed at $\sim 75{ }^{\circ} \mathrm{C}(348 \mathrm{~K})$ and continued up to $\sim 85{ }^{\circ} \mathrm{C}$, with the crystals darkening in appearance. Above $80^{\circ} \mathrm{C}$ small bubbles can be seen to travel along the a-axis. Above $100{ }^{\circ} \mathrm{C}$ visible water droplets emerge from defects on the dominant, visible crystal faces. If the crystals are heated in air, there being no oil present, surface crystal growth is not seen. A change in the birefringence pattern is found, progressing along the a-axis, suggesting this as the direction of dehydration (see section 9 of the Supporting Information). The localised water activity for the two sample preparations is likely to be different. For the crystals heated in air the water can escape however for the crystals heated in the oil the water is potentially retained, enabling a higher local water activity, so influencing the dehydration behaviour.

Deleted: Figure 7

Formatted: Highlight 

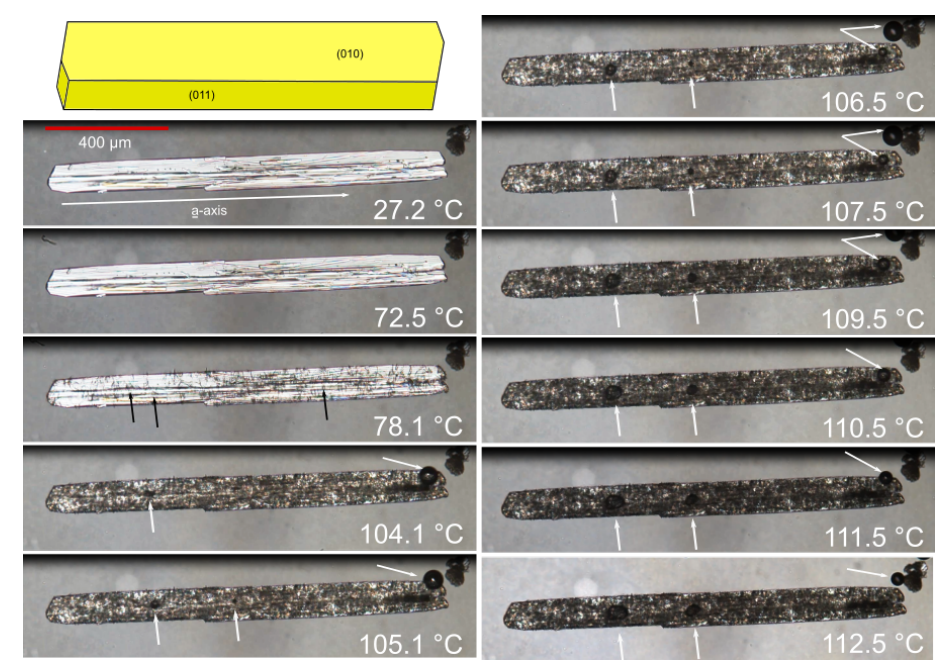

Figure 7 Dehydration of fluconazole MH crystals (immersed in silicone oil) as a function of temperature, showing the evolution of water droplets (arrows) from the visible, dominant, crystal faces (011) and (010). Viewed between partially crossed polarising filters. Crystal indexing indicating that the axis runs parallel to the length of the crystal_top morphology left is a diagrammatic representation of the experimental morphology).

Impact of Temperature on lattice parameters. In order to compare the influence of temperature on the crystal structure of fluconazole $\mathrm{MH}$, we compared the lattice parameters of the single crystal structures solved at 100K (IVUQIZ02 ${ }^{58}$ ) and 293K (IVUQIZ ${ }^{42}$ ) in Table 1. The comparison reveals that the lattice expands more significantly along the c-axis $(0.157$ $\AA$ ) than the $\underline{a}$ or $\underline{b}$-axis $(0.055$ and $0.050 \AA$ respectively). Expansion along the $\underline{\underline{c}}$-axis was also found to be more significant on heating the MH above RT, as found from the displacement of the relevant peaks in the hot stage pXRD patterns (see section 10 of the Supporting Information).

Table 1 Lattice parameters for the fluconazole MH structure, comparing low (100K) and room temperature (293K) structures.

\begin{tabular}{|c|c|c|c|}
\hline $\begin{array}{l}\text { CSD Refcode } \\
\text { Temperature }\end{array}$ & $\begin{array}{c}\text { IVUQIZ02 } \\
100 \mathrm{~K} \\
\end{array}$ & $\begin{array}{c}\text { IVUQIZ } \\
293 K\end{array}$ & $\begin{array}{c}\Delta \\
(293 K-100 K)\end{array}$ \\
\hline $\mathrm{a}(\AA)$ & 5.571 & 5.626 & 0.055 \\
\hline $\mathrm{b}(\AA)$ & 11.687 & 11.737 & 0.050 \\
\hline$c(\AA)$ & 12.149 & 12.306 & 0.157 \\
\hline$\alpha\left(^{\circ}\right)$ & 70.99 & 71.24 & 0.25 \\
\hline$\beta\left(^{\circ}\right)$ & 78.91 & 79.87 & 0.96 \\
\hline$\gamma\left({ }^{\circ}\right)$ & 84.63 & 84.38 & -0.24 \\
\hline volume $\left(\AA^{3}\right)$ & 733.48 & 756.68 & 23.20 \\
\hline
\end{tabular}

Formatted: Highlight

Deleted: . Including

Deleted: Table 1 


\subsection{Activation Energies of the Dehydration Process}

Dehydration of the MH was studied isothermally. From the data, activation energies $\left(\mathrm{E}_{\mathrm{a}}\right)$ are derived as a function of the dehydration conversion fraction $(\alpha)$. We observe a marked drop in $E_{a}$ with respect to conversion fraction $(\alpha)$ from $77 \mathrm{~kJ} / \mathrm{mol}$ at $\alpha=0.1$ down to $38 \mathrm{~kJ} / \mathrm{mol}$ for $\alpha=0.9$ (Figure 8) suggesting that dehydration becomes easier as the conversion progresses. The initial $E_{a}$ measured here is in good agreement with previous values calculated for fluconazole monohydrate $(90 \pm 11 \mathrm{~kJ} / \mathrm{mol})_{\Lambda . .}^{43}$ using the three-dimensional phase boundary model.

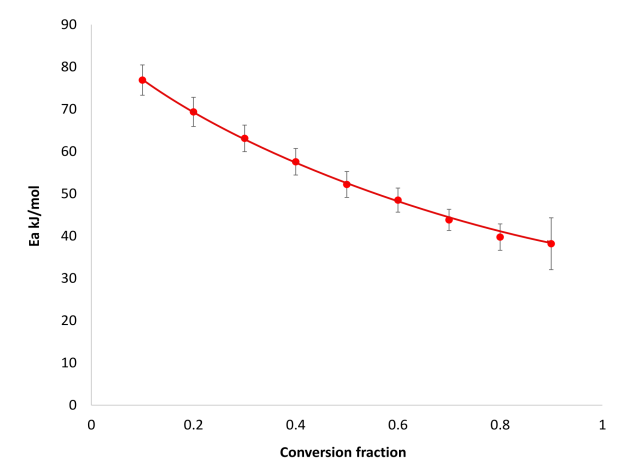

Figure 8 Activation energy (Ea) for dehydration of fluconazole monohydrate showing $95 \%$ confidence intervals from replicate analysis $(n=5)$.

The initial value seen for fluconazole is in line with the $E_{a}$ found for dehydration of other organic hydrates: nedocromil $\mathrm{Mg}$ pentahydrate $\left(70 \mathrm{~kJ} / \mathrm{mol}^{59}\right)$, beclomethasone dipropionate monohydrate $\left(70 \mathrm{~kJ} / \mathrm{mol}^{60}\right)$, cefadroxil monohydrate $\left(63 \mathrm{~kJ} / \mathrm{mol}^{60}\right)$, indinavir monohydrate $\left(70 \mathrm{~kJ} / \mathrm{mol}^{60}\right)$, neotame monohydrate $\left(79 \mathrm{~kJ} / \mathrm{mol}^{60}\right)$, ampicillin trihydrate $\left(72 \mathrm{~kJ} / \mathrm{mol}^{60}\right)$, 4-hydroxynicotinic acid hemihydrate $\left(85 \mathrm{~kJ} / \mathrm{mol}^{61}\right)$ and neotame monohydrate $\left(75 \mathrm{~kJ} / \mathrm{mol}^{62}\right)$. However values as high as $199 \mathrm{~kJ} / \mathrm{mol}$ and as low as $30 \mathrm{~kJ} / \mathrm{mol}$ have been reported for piroxicam monohydrate ${ }^{63}$ and eprosartan mesylate dihydrate ${ }^{19}$ respectively (see section 5 of the supporting information). There is limited data for the influence of conversion fraction on $E_{a}$, however a decrease in $E_{a}$, with an increase in conversion fraction, was found for nedocromil Na trihydrate $(80 \text { to } 60 \mathrm{~kJ} / \mathrm{mol})^{64}$ and mildronate dihydrate $(105$ to $75 \mathrm{~kJ} / \mathrm{mol}){ }^{23}$

Since the activation energies measured for the fluconazole $\mathrm{MH}$ at the beginning of the process are similar in magnitude to those reported for various other crystal growth and nucleation processes ${ }^{65-71}$ it is reasonable to assume that nucleation and growth of the anhydrous form, $\mathrm{AH}-\mathrm{C}$, is the dominant process controlling the kinetics of fluconazole $\mathrm{MH}$ dehydration at the beginning of the process. As dehydration progresses, the activation energy decreases to $38 \mathrm{~kJ} / \mathrm{mol}$ which is in line with the strength of approximately two hydrogen bonds.
Formatted: Highlight

Formatted: Highlight
Formatted: Highlight
Formatted: Highlight
Formatted: Highlight




\subsection{Molecular Dynamics Simulations}

\section{0 ps NPT simulations at various temperatures}

When analysing average cell volume and density, derived from our MD simulations at various temperatures, (Figure 9) it is found that, for an increase in temperature, the unit cell density decreases and the volume increases. The obtained values are in good agreement with those known from the X-ray single crystal data at $100 \mathrm{~K}$ and $298 \mathrm{~K}$. Our simulations, however, slightly overestimate the volume and underestimate the density. This may be interpreted that our simulation temperatures correspond with slightly higher "real" temperatures. This can often be the case since forcefields are usually fitted to real non $0 \mathrm{~K}$ structural data. Thus, these forcefields have some thermal "contamination" which may result in the simulation temperatures corresponding to higher real temperatures.

The temperature shift was estimated to be $\sim 44 \mathrm{~K}$ by matching our predicted unit cell volumes with the single crystal experimental volumes. Thus, our simulations at $200 \mathrm{~K}$ correspond to a $244 \mathrm{~K}$ real temperature $(\mathrm{rT})$. The simulations were carried out at $100 \mathrm{~K}, 200 \mathrm{~K}, 249 \mathrm{~K}, 298 \mathrm{~K}$, $347 \mathrm{~K}$ and $396 \mathrm{~K}$. Thus, the real temperatures of our simulations correspond to $144 * \mathrm{~K}, 244 * \mathrm{~K}$, $293 * \mathrm{~K}, 342 * \mathrm{~K}, 391 * \mathrm{~K}$ and $440 * \mathrm{~K}$; with the asterisk symbolizing that these are the real temperatures, rather than the simulation values. To enable a more direct comparison with the experimental outcome, we will refer to the real temperatures for our simulations from now on.

At $440 * \mathrm{~K}$ (rT, Figure 9 right) we see big changes in density and volume driven mostly by a significant loss of crystal structure and an increase in mobility of the waters in the simulation box. This is expected, as we are over $60 \mathrm{~K}$ above the dehydration temperature.
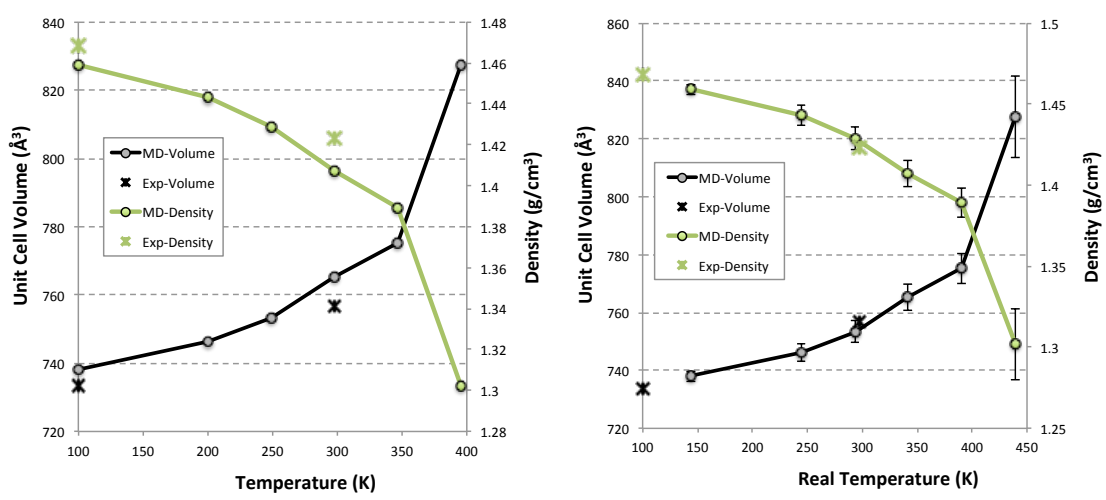

Figure 9 Unit cell volume (black) and density (green) of fluconazole MH as a function of simulation temperature (left). Right plot applies a $44 \mathrm{~K}$ correction to the simulation temperature to provide the "real" temperature. Experimental values are given as crosses.
Deleted: Figure 9

Deleted: Figure 9 
An analysis of the radial distribution functions (rdfs) of fluconazole-fluconazole (Of...Of) and water-water (Ow...Ow) oxygen atom pairs (Figure 10), allowed for the evolution of the MH structure to be monitored as a function of temperature. For simplicity, we show three temperatures in Figure 10, The lowest temperature rdfs, 144*K, have well-defined sharp peaks for both the fluconazole Of... Of and the water Ow...Ow. The most characteristic peaks for the Of...Of and Ow...Ow rdfs are both located at $\sim 5.6 \AA$ respectively. This value corresponds with the stacking (by translation) of the fluconazole molecules along the a-axis (5.5 and $5.6 \AA$ in the $100 \mathrm{~K}$ and $298 \mathrm{~K}$ structures). At $342 * \mathrm{~K}$ this peak is clearly shifted to higher values for the Of...Of and becomes very wide in the Ow...Ow. This indicates that water has a higher mobility at this intermediate temperature. At $440 * \mathrm{~K}$, the structure of the fluconazole (Of...Of) is considerably disordered, and the structure of water changes completely. For the Ow... Ow rdf we observe a very large peak at $2.65 \AA$. This is representative of water-water hydrogen bonding. Whilst at lower temperatures the waters remain in pockets and are not able to interact with each other, at $440 * \mathrm{~K}$ they have enough mobility to migrate in the lattice and start forming water clusters.
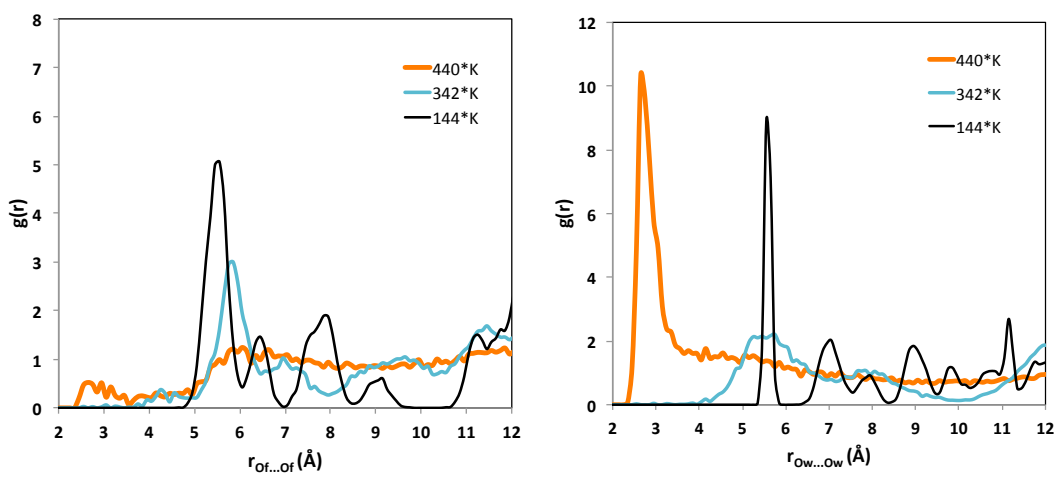

Figure 10 Radial distribution functions for $0 . . . O$ pairs typical of the fluconazole (left, Of...Of) and water (right, Ow...Ow) structures at three different simulation temperatures.

We analysed the conformational changes occurring in the fluconazole molecule as the temperature was increased and the cell progressively expands. At $293 * \mathrm{~K}$ and above, the torsions of fluconazole become fairly mobile, and librate more significantly around the preferred torsion values (peak maxima in the distributions). An analysis of the distribution of all fluconazole torsions reveals an important shift in conformation of fluconazole around the $\mathrm{OH}$ torsion $\left(\tau_{\mathrm{OH}}\right.$, Figure 11$)$. At low temperature, $144 * \mathrm{~K}, 100 \%$ of fluconazole molecules have a $\tau_{\mathrm{OH}} \approx \pm 180^{\circ}$, with no other $\mathrm{OH}$ conformations present. Rotation of the $\mathrm{OH}$ is possible within the hydrate structure and conformations with $\tau_{\mathrm{OH}}$ values between $-100^{\circ}$ to $100^{\circ}$ start to appear at intermediate temperatures, these dominate at the high $440 * \mathrm{~K}$ temperature. In the hydrate lattice, when $\tau_{\mathrm{OH}}$ stays around $\pm 180^{\circ}$, the fluconazole molecule is able to form a
Deleted: Figure 10

Deleted: Figure 10 
hydrogen bond with the water molecule in the lattice (Figure 12). Upon rotation of the $\mathrm{OH}$ to $\tau_{\mathrm{OH}} \approx \pm 60^{\circ}$, the fluconazole-water hydrogen bond breaks. This has two consequences: i) a strengthening of the fluconazole-fluconazole interaction, and ii) a weakening of the fluconazole-water interactions, thus increasing the mobility of the water molecules. The rotation of the $\mathrm{OH}$ functionality now provides an orientation found in the dehydration product (AH-C with $\tau_{\mathrm{OH}}=54^{\circ}$ ) and enables it to hydrogen bond to a $\mathrm{N}$ atom in the triazole ring of an adjacent fluconazole (originally not involved in hydrogen bonding), promoting the hydrogen bonding found in AH-C.

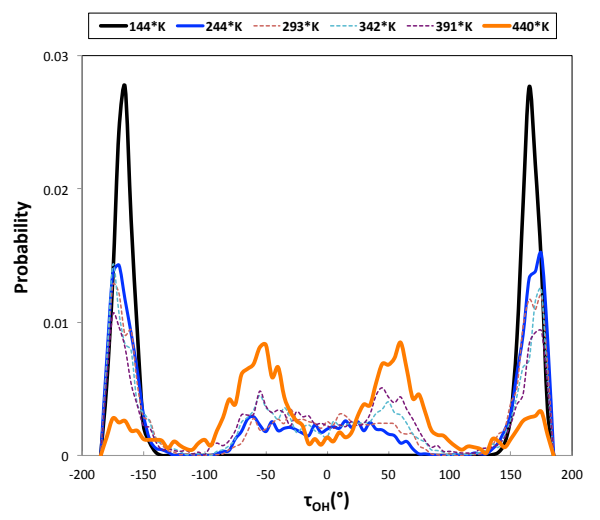

Figure 11 Distribution of $\tau_{\mathrm{OH}}$ various simulation temperatures.

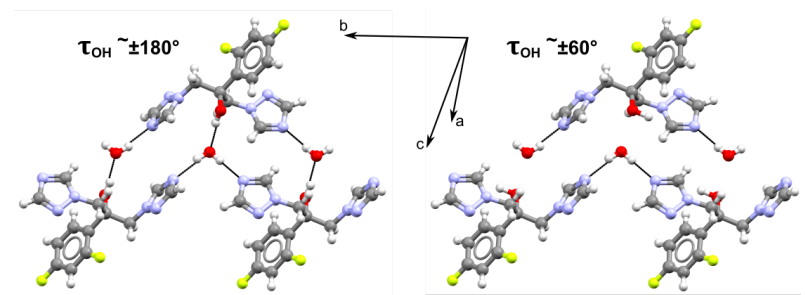

Figure 12 Dominant fluconazole conformation at low temperature $\left(\tau_{\mathrm{OH}} \approx \pm 180^{\circ}\right)$ allows for a fluconazolewater hydrogen bond, this breaks upon $\mathrm{OH}$ rotation to $\tau_{\mathrm{OH}} \approx 60^{\circ}$. Including cell axis directions.

To illustrate this further, we plotted the average fraction of $\mathrm{MH} \mathrm{OH}$ conformations (conformations with $\tau_{\mathrm{OH}}$ around $\pm 160^{\circ} \pm 40^{\circ}$ ) and the derived water diffusion coefficient as a function of temperature in Figure 13. As the temperature is increased, the $\mathrm{OH}$ groups change conformation away from that in the monohydrate. When less than $50 \%$ of the fluconazole molecules have changed conformation, the water molecules are able to diffuse, this starting above $342 * \mathrm{~K}$, as we approach the experimental dehydration temperature.
Deleted: Figure 12

Formatted: Highlight

\begin{tabular}{l} 
Deleted: , \\
Formatted: Highlight \\
Deleted: where \\
Deleted: $>$ \\
Deleted: 20 \\
Deleted: or $\tau_{\mathrm{OH}}<120^{\circ}$ \\
Deleted: : Figure 13 shows that a \\
\hline
\end{tabular}




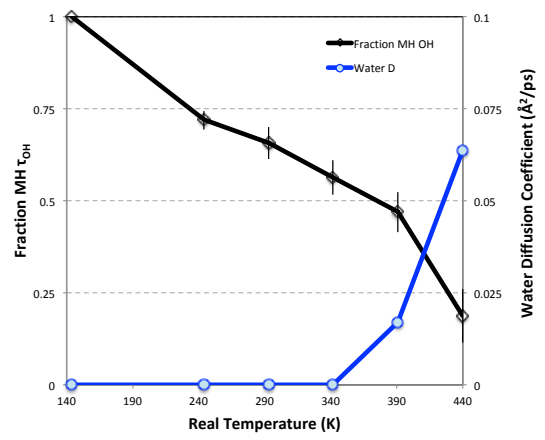

Figure 13. Fraction of MH OH conformations (black) and water diffusion coefficient (blue) as a function of temperature.

\section{$10 \mathrm{~ns}$ NPT simulations at $293 * \mathrm{~K}$ and $342 * \mathrm{~K}$}

In order to further understand the behaviour of the system at temperatures close to dehydration $(340-380 \mathrm{~K}), 10 \mathrm{~ns}$ NPT simulations were carried out at two temperatures: $293 * \mathrm{~K}$ and $342 * \mathrm{~K}$. In Figure 14, we monitor the evolution of the fraction of MH OH conformations as a function of time as well as density. Both properties remain fairly constant for the simulation at $293 * \mathrm{~K}$. The correlation between the local fluctuations in $\mathrm{OH}$ conformations and the density, is quite striking. At $293 * \mathrm{~K}$ the water is not able to diffuse in the lattice during the entire simulation time (the mean squared displacement of water molecules is practically 0 ).
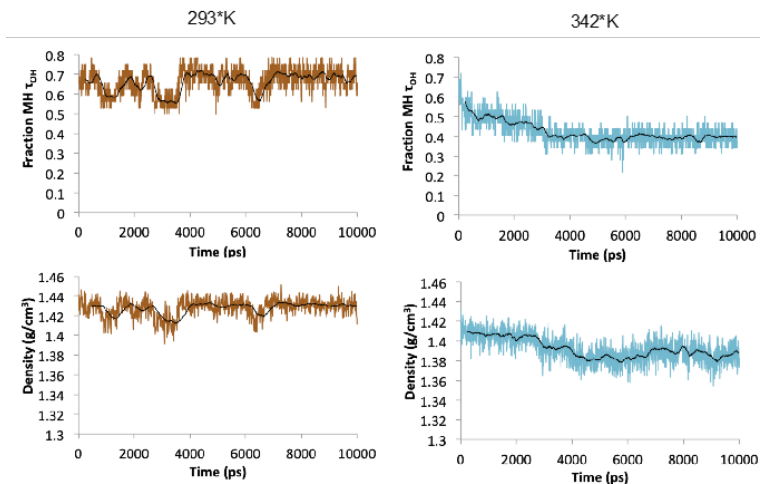

Figure 14 Time evolution of the fraction of $\mathrm{MH} \mathrm{OH}$ conformation and density at two temperatures. Values for the simulation are shown in coloured lines; to aid visualisation the moving average of 50 data points is given in black. 
For the simulation time at $342 * \mathrm{~K}$, we observe no water diffusion during the first 500 ps of the simulation. During this time, conformational change along the $\mathrm{OH}$ group takes place and the fraction of $\mathrm{MH} \mathrm{OH}$ conformations goes down significantly from around 0.65 to a plateau at around 0.40 . When the $\mathrm{MH} \mathrm{OH}$ fraction is below $\sim 0.5$, water molecules are able to diffuse in the lattice from one pocket to another. The process is not frequent at first but becomes more frequent when the simulation reaches the 0.4 fraction plateau. An analysis of the mean squared displacement of the water molecules (Figure 15) in the unit cell, along the three different cell dimensions, reveals that diffusion along the $\mathrm{a}$ and $\mathrm{b}$ directions is much more prevalent than the $\mathrm{c}$ direction of the lattice.

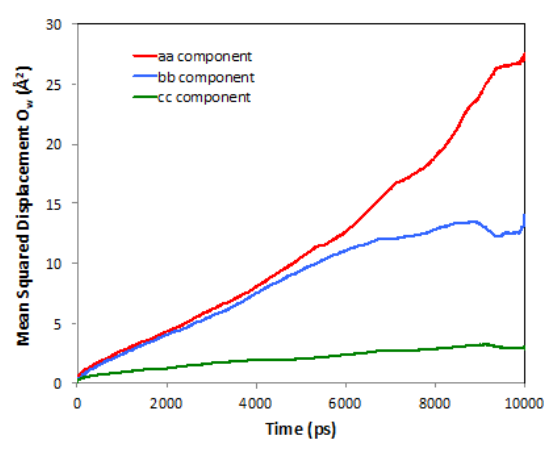

Figure 15 Mean squared displacements of water molecules along the three different cell dimensions in the $342 * \mathrm{~K}$ simulation.

\section{Discussion}

The thermodynamic stability of a hydrate is governed by temperature, pressure and water activity; hence it would be expected that heat, low water activity (relative humidity) or a combination of these could result in dehydration. Fluconazole monohydrate (MH) was shown to dehydrate at lower temperatures $\left(30{ }^{\circ} \mathrm{C}\right)$, only on exposure at $0 \% \mathrm{RH}$. On heating the dehydration threshold was observed in the range $50-75{ }^{\circ} \mathrm{C}$, dependent on experimental conditions. Dehydration involved the loss of one mole of water as a single event, with anhydrous, metastable polymorph, $\mathrm{AH}-\mathrm{C}$ as the product.

There is evidence that water can migrate along the $\underline{a}$ and $\underline{b}$-axis. Upon dehydration, changes in the birefringence pattern progress along the a-axis, suggesting this as the direction of dehydration for a sample heated in air. For a sample heated in silicone oil, however, water is observed to diffuse along the a-axis prior to the appearance of water droplets on the surface of the dominant crystallographic faces, $(010)$ and (011), this requiring water to migrate along the b-axis. Thermal expansion was found to be dominant in the direction of the c-axis. The experimentally observed dehydration behaviour mirrors that revealed through the molecular

Formatted: Highlight
Deleted: clusters are
Deleted: travel


dynamics simulations, where water diffusion is much more prevalent along the $\underline{a}$ and $\underline{b}$-axis than the c-axis of the lattice.

Molecular dynamics simulations, at different temperatures, revealed changes to the radial distribution functions (rdfs) of fluconazole-fluconazole (Of...Of) and water-water (Ow...Ow) oxygen atom pairs, and allowed us to explore the mobility of water in the MH structure as a function of temperature. At lower temperatures the waters remain in pockets and are not able to interact with each other, at $342^{*} \mathrm{~K}\left(69^{\circ} \mathrm{C}\right)$ water mobility increases, with a further increase in temperature providing enough mobility to allow water to migrate within the lattice and start forming water clusters. We note, however, that this might be an artefact of the simulations since surfaces have not been modelled so the water was not able to leave the system but just diffuse within the lattice.

The key step required to initiate the dehydration mechanism is a change in the molecular conformation of fluconazole, through the rotation of the $\mathrm{OH}$ functionality. As the temperature is increased, the $\mathrm{OH}$ groups change conformation away from that found in the monohydrate ( $\tau_{\mathrm{OH}} \approx \pm 180^{\circ}$ ) to that found in AH-C $\left(\tau_{\mathrm{OH}} \approx \pm 60^{\circ}\right)$. At lower temperatures, the majority of molecules adopt the $\mathrm{MH} \mathrm{OH}$ conformation, whilst the proportion of molecules in the simulation cell adopting the $\mathrm{AH}-\mathrm{C} \mathrm{OH}$ conformation increases steadily as the temperature increases. When approximately half of the fluconazole molecules have adopted $\mathrm{AH}-\mathrm{C} \mathrm{OH}$ conformations, we observe a noticeable increase in water diffusion; this occurs at a simulation temperature close to that observed experimentally. The conformational change orients the $\mathrm{OH}$ group such that it is able to donate to a nitrogen atom in the triazole ring of an adjacent fluconazole. Water exists in environment $5,{ }^{45}$ forming three hydrogen bonds, breaking of the $\mathrm{OH}$ to water hydrogen bond through the conformational change weakens the fluconazole-water interactions. This temperature dependant conformational change, found in the conformation of the $\mathrm{OH}$ group, appears to be a key initiation factor in the disruption of the hydrogen bond network in the MH structure.

Simulating fluctuations in the $\mathrm{OH}$ group conformation over time $(10 \mathrm{~ns})$ suggests that both conformation and density remain fairly constant for the simulation at $293^{*} \mathrm{~K}$, whereas conformational change is seen for simulations at the dehydration threshold temperature $(342 * \mathrm{~K})$. During the simulations, conformational change of the $\mathrm{OH}$ group takes place with the fraction of $\mathrm{MH} \mathrm{OH}$ conformations decreasing from around 0.65 to 0.40 . At $293 * \mathrm{~K}$ water is not able to diffuse in the lattice. At $342 * \mathrm{~K}$, for the first $500 \mathrm{ps}$ of the simulation, an increasing number of fluconazole molecules changes their $\mathrm{OH}$ conformation yet there was no water diffusion observed. However, when the $\mathrm{MH} \mathrm{OH}$ fraction is below $\sim 0.5$, water molecules are able to diffuse in the lattice from one pocket to another, this process becoming more frequent when the simulation reaches the 0.4 fraction plateau. The conformational change can act to initiate the destabilisation of the MH hydrogen bonding however, the water is not free to migrate through the lattice until a significant fraction of the $\mathrm{OH}$ groups have changed conformation.

Experimentally a decrease in the dehydration activation energy is found, dropping from a value of $77 \mathrm{~kJ} / \mathrm{mol}$ at a conversion fraction of $\alpha=0.1$ to $38 \mathrm{~kJ} / \mathrm{mol}$ at $\alpha=0.9$, this implies that 
there is a decrease in the barrier as dehydration progresses. Changes in the conformation destabilise the hydrogen bonding network for the $\mathrm{MH}$ and promote the network for the anhydrous form. Initially nucleation of $\mathrm{AH}-\mathrm{C}$ is the dominant factor influencing the dehydration activation energy, with growth of $\mathrm{AH}-\mathrm{C}$ progressing through the $\mathrm{MH}$ crystal as water is lost. Interestingly, at higher conversion fractions, the activation energy for the dehydration is $\sim 38 \mathrm{~kJ} / \mathrm{mol}$, which approximately equates to two water-fluconazole hydrogen bonds. This is revealing since it indicates that after enough anhydrous form has nucleated and grown, the diffusion of water within the MH lattice (for which two hydrogen bonds need to be broken) becomes the rate controlling mechanism. Water clusters may disrupt the particle, thus creating a path for continued dehydration. A change in birefringence, observed during dehydration (hot stage microscopy), suggests that a single crystal of $\mathrm{MH}$ dehydrates to a polycrystalline particle of AH-C. As a result, voids are likely to exist between AH-C crystals, allowing for water movement through the particle.

$\mathrm{MH}$ dehydrates to $\mathrm{AH}-\mathrm{C}$ rather than the thermodynamically stable polymorph $\left(\mathrm{AH}-\mathrm{B}^{35}\right)$ or metastable polymorph $\left(\mathrm{AH}-\mathrm{A}^{35}\right)$. It may be expected that dehydration products would represent the energetically favoured kinetic outcome and not necessarily the thermodynamically stable anhydrous form. AH-C does not represent the stable anhydrous form of fluconazole at room temperature and is extremely challenging to crystallise from solution, ${ }^{35}$ yet readily forms as the MH dehydration product regardless of the conditions used. We notice two important factors here which help rationalise why MH dehydrates towards the AH-C: i) the conformational similarity and ii) the crystal structure similarity between the $\mathrm{MH}$ and the AH-C.

With regards to the conformation, we studied this in detail in our previous work. ${ }^{35}$ The conformation in $\mathrm{AH}-\mathrm{C}$ is extremely similar to the $\mathrm{MH}$ conformation: it only requires rotation of the $\mathrm{OH}$ from $\tau_{\mathrm{OH}} \approx \pm 100^{\circ}$ (in the $\mathrm{MH}$ ) to $\tau_{\mathrm{OH}} \approx \pm 60^{\circ}$ (in $\mathrm{AH}-\mathrm{C}$ ). We have shown that such conformational change already occurs within the $\mathrm{MH}$ crystal structure before dehydration commences. When the dehydration starts, over $50 \%$ of the fluconazole molecules already have the conformation found for AH-C. The conformation is identical to the AH-A polymorph but very different to the AH-B polymorph. ${ }^{35}$

With regards to the similarity in the crystal structures, Figure 16, compares the structures of the $\mathrm{MH}$ and AH-C. The (01I) plane in $\mathrm{MH}$ can be aligned with the (200) plane in the AH-C structure, likewise the (011) plane in the $\mathrm{MH}$ can be aligned with the (002) plane in the AH-C structure. Comparing the position of the fluconazole molecules in the $\mathrm{MH}$ structure to those found in the AH-C structure the differences reflect the expansion required to incorporate a water molecule in the structure, there being very small changes in the angle of adjacent molecules (Table 2). Comparing (100) in the $\mathrm{MH}$ to $(020)$ for AH-C, formation of the AH-C structure requires the rotation of alternate fluconazole molecules. The $\mathrm{OH}$ group conformational change potentially acting to initiate this process, with the empty water pocket providing molecular space for movement of the triazole rings.

Deleted: Figure 16

Deleted: Table 2 

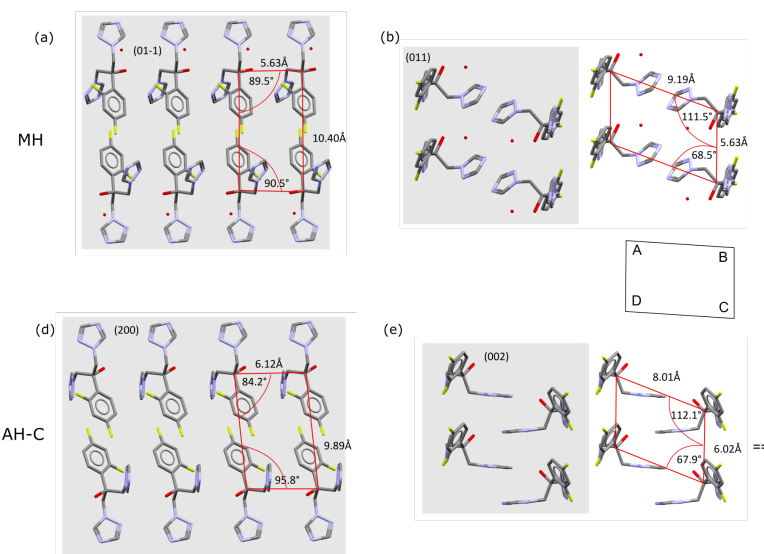

(e)

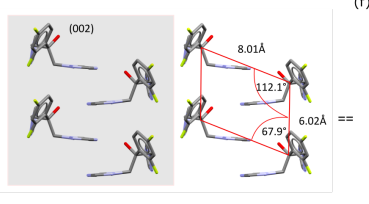

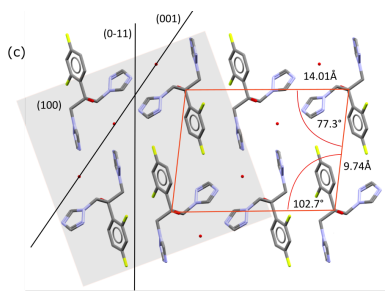

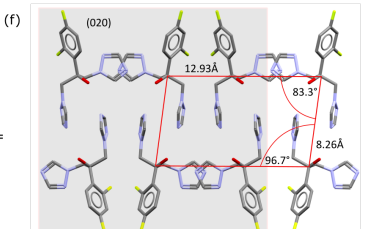

Figure 16 Structural similarity found between the MH (a,b,c) and AH-C (d,e,f) relative to the (200), (002) and (020) planes in $\mathrm{AH}-\mathrm{C}$. Lengths $\mathrm{AB}$ and $\mathrm{BC}$ and angles $\mathrm{ABC}$ and $\mathrm{BCD}$ were measured from the central carbon atom of the fluconazole molecules.

Table 2 Change in the distance and relative angles between adjacent fluconazole molecules comparing the AH-C and MH structures.

\begin{tabular}{lcccc}
\hline plane in $\mathbf{M H}$ vs AH-C & $\begin{array}{c}\Delta \text { length } \\
\mathbf{A B}(\boldsymbol{\AA})\end{array}$ & $\begin{array}{c}\Delta \text { length } \\
\mathbf{B C}(\boldsymbol{\AA})\end{array}$ & $\begin{array}{c}\Delta \text { angle } \\
\mathbf{A B C}\left({ }^{\circ}\right)\end{array}$ & $\begin{array}{c}\Delta \text { angle } \\
\mathbf{B C D}\left({ }^{\circ}\right)\end{array}$ \\
\hline$(011)$ vs $(200)$ & -0.49 & 0.51 & 5.3 & -5.3 \\
$(011)$ vs $(020)$ & 1.18 & -0.39 & -0.6 & 0.6 \\
$(100)$ vs $(020)$ & 1.08 & 1.48 & -6 & 6 \\
\hline
\end{tabular}

Lengths and angles were measured from the central carbon atom of the fluconazole molecule to the two adjacent molecules found perpendicular to the plane as depicted in Figure 16, The difference is taken as the values measured for $\mathrm{AH}-\mathrm{C}$ subtracted from values measured for the $\mathrm{MH}$.

\section{Conclusions}

We have studied the dehydration behaviour of fluconazole monohydrate, combining experimental analytical techniques with molecular dynamics simulations. Molecular dynamics simulations revealed a possible initiating mechanism for dehydration: as the temperature is increased, a significant proportion of molecules change conformation around the $\mathrm{OH}$ group, this weakening the water-fluconazole hydrogen bonding. This conformational change, combined with lattice expansion of the c-axis, allows for greater mobility of the water to migrate along the $\underline{a}$ and $\underline{b}$-axis during the dehydration process. Conformational change also promotes formation of the anhydrous product, metastable polymorph $\mathrm{AH}-\mathrm{C}$, since the $\mathrm{OH}$ rotation allows for the formation of a fluconazole-fluconazole hydrogen bond. Comparing the crystal structures of $\mathrm{AH}-\mathrm{C}$ with $\mathrm{MH}$, striking conformational and structural similarities are found, therefore AH-C is expected as the dehydration product. Our work

Formatted: Highlight

Formatted: Highlight

Deleted: Figure 16 
reveals that conformational change, instigated by thermal motion, may be a key factor in understanding the thermal stability of organic hydrates.

\section{Associated Content}

\section{Supporting Information}

Form identification by pXRD on the crystallised $\mathrm{MH}$. A new crystal structure for $\mathrm{MH}$ at 298K, including crystal indexing (CCDC Deposition Number 2007854). Identification of the dominant crystallographic face. Dehydration data and activation energy calculations with respect to conversion fraction, including a summary of literature values reported for the dehydration of 20 organic hydrates. Packing similarity $\operatorname{rmsd}_{20}$ values from geometry optimisation and cell parameters for the MD simulations are tabulated. The influence of DSC sample pan configuration and heating rate is summarised. Dehydration of $\mathrm{MH}$ at $30{ }^{\circ} \mathrm{C}$ and 0 $\%$ RH. HSM images for a water cluster traveling along the a-axis including images for a crystal heated in air. Thermal lattice expansion identified through comparison of $100 \mathrm{~K}$ and room temperature simulated $\mathrm{pXRD}$ patterns and hot stage $\mathrm{pXRD}$ patterns.

\section{Accession Codes}

CCDC 2007854 contains the supplementary crystallographic data for this paper. The data can be obtained free of charge via www.ccdc.cam.ac.uk/data_request/cif, or by emailing data_request@ccdc.cam.ac.uk, or by contacting The Cambridge Crystallographic Data Centre, 12 Union Road, Cambridge CB2 1EZ, UK; fax: +44 1223336033.

\section{Author information}

\section{Corresponding Authors}

*E-mail: pat.basford@pfizer.com and aurora.cruzcabeza@manchester.ac.uk

\section{ORCID}

Patricia A. Basford

Christopher A. Cameron

Aurora J. Cruz-Cabeza

\section{Author Contributions}

P.A.B. designed and executed most experiments as well as made major contributions to the writing of the manuscript. C.A.C. contributed crystallography expertise. A.J.C.C. has contributed with molecular dynamics simulations, project design discussions, and manuscript writing. 


\section{Acknowledgements}

The authors thank Prof. Roger Davey and Dr Bob Doherty for helpful discussions. P.A.B. thanks Mike Smith for advice on statistical error and Pfizer for materials, use of their equipment, laboratories and funding.

\section{References}

1. Brittain, H. G. M., K. R.; Boerrigter, S. X. M., Polymorphism in Pharmaceutical Solids. Informa Healthcare: New York, London,: 2009; Vol. 192.

2. Haleblian, J. K., Characterization of habits and crystalline modification of solids and their pharmaceutical applications. J. Pharm. Sci. 1975, 64 (8), 1269-88.

3. Cruz-Cabeza, A. J.; Reutzel-Edens, S. M.; Bernstein, J., Facts and fictions about polymorphism. Chem. Soc. Rev. 2015, 44 (23), 8619-35.

4. Morris, K. R.; Rodriguez-Hornedo, N., Encyclopedia of pharmaceutical technology. Marcel Dekker: New York, 1993; Vol. 7.

5. Vippagunta, S. R.; Brittain, H. G.; Grant, D. J. W., Crystalline solids. Adv. Drug Delivery Rev. 2001, 48 (1), 3-26.

6. Griesser, U. J., The importance of solvates. Polymorphism in the Pharmaceutical Industry. Wiley-VCH Verlag GmbH \& Co.: 2006.

7. Burger, A.; Sturm, S.; Bolitschek-Dialer, R. D., Polymorphism and pseudopolymorphism of sulfametrole. Solubility and tablet forming properties. Pharm. Ind. 1988, 50 (12), 1396-1405.

8. Brenner, G.; Roberts, F. E.; Hoinowski, A.; Budavari, J.; Powell, B.; Hinkley, D.; Schoenewaldt, E., Effect of crystalline form on the air-oxidation of steroidal $11 \beta$-ols to 11ones. Angew. Chem., Int. Ed. Engl. 1969, 8 (12), 975-6.

9. Byrn, S. R.; Sutton, P. A.; Tobias, B.; Frye, J.; Main, P., Crystal structure, solid-state NMR spectra, and oxygen reactivity of five crystal forms of prednisolone tert-butylacetate. $J$. Am. Chem. Soc. 1988, 110 (5), 1609-14.

10. Tian, F.; Qu, H.; Zimmermann, A.; Munk, T.; Jørgensen, A. C.; Rantanen, J., Factors affecting crystallization of hydrates. J. Pharm. Pharmacol. 2010, 62 (11), 1534-1546.

11. Shefter, E.; Higuchi, T., Dissolution behavior of crystalline solvated and nonsolvated forms of some pharmaceuticals. J. Pharm. Sci. 1963, 52 (8), 781-91.

12. Boetker, J. P.; Rantanen, J.; Arnfast, L.; Doreth, M.; Raijada, D.; Loebmann, K.; Madsen, C.; Khan, J.; Rades, T.; Mullertz, A.; Hawley, A.; Thomas, D.; Boyd, B. J., Anhydrate to hydrate solid-state transformations of carbamazepine and nitrofurantoin in biorelevant media studied in situ using time-resolved synchrotron X-ray diffraction. Eur. $J$. Pharm. Biopharm. 2016, 100, 119-127.

13. Wong, M. W. Y.; Mitchell, A. G., Physicochemical characterization of a phase change produced during the wet granulation of chlorpromazine hydrochloride and its effects on tableting. Int. J. Pharm. 1992, 88 (1-3), 261-73.

14. Otsuka, M.; Hasegawa, H.; Matsuda, Y., Effect of polymorphic forms of bulk powders on pharmaceutical properties of carbamazepine granules. Chem. Pharm. Bull. 1999, $47(6), 852-856$.

15. Chongprasert, S.; Griesser, U. J.; Bottorff, A. T.; Williams, N. A.; Byrn, S. R.; Nail, S. L., Effects of Freeze-Dry Processing Conditions on the Crystallization of Pentamidine Isethionate. J. Pharm. Sci. 1998, 87 (9), 1155-1160. 
16. Garner, W. E., Chemistry of the solid state. Butterworths Scientific Publications: London, 1955.

17. Braun, D. E.; Griesser, U. J., Stoichiometric and Nonstoichiometric Hydrates of Brucine. Cryst. Growth Des. 2016, 16 (10), 6111-6121.

18. Braun, D. E.; Gelbrich, T.; Kahlenberg, V.; Tessadri, R.; Wieser, J.; Griesser, U. J., Stability of Solvates and Packing Systematics of Nine Crystal Forms of the Antipsychotic Drug Aripiprazole. Cryst. Growth Des. 2009, 9 (2), 1054-1065.

19. Sheng, J.; Venkatesh, G. M.; Duddu, S. P.; Grant, D. J. W., Dehydration Behavior of Eprosartan Mesylate Dihydrate. J. Pharm. Sci. 1999, 88 (10), 1021-1029.

20. Garnier, S.; Petit, S.; Coquerel, G., Dehydration Mechanism and Crystallization Behavior of Lactose. J. Therm. Anal. Calorim. 2002, 68 (2), 489-502.

21. Braun, D. E.; Koztecki, L. H.; McMahon, J. A.; Price, S. L.; Reutzel-Edens, S. M., Navigating the Waters of Unconventional Crystalline Hydrates. Mol. Pharmaceutics 2015, 12 (8), 3069-3088.

22. Ahlqvist, M. U. A.; Taylor, L. S., Water dynamics in channel hydrates investigated using H/D exchange. Int. J. Pharm. 2002, 241 (2), 253-261.

23. Bērziņšs, A.; Actinšs, A., Effect of Experimental and Sample Factors on Dehydration Kinetics of Mildronate Dihydrate: Mechanism of Dehydration and Determination of Kinetic Parameters. J. Pharm. Sci. 2014, 103 (6), 1747-1755.

24. Braun, D. E.; Bhardwaj, R. M.; Arlin, J.-B.; Florence, A. J.; Kahlenberg, V.; Griesser, U. J.; Tocher, D. A.; Price, S. L., Absorbing a Little Water: The Structural, Thermodynamic, and Kinetic Relationship between Pyrogallol and Its Tetarto-Hydrate. Cryst. Growth Des. 2013, 13 (9), 4071-4083.

25. Perrier, P.; Byrn, S. R., Influence of crystal packing on the solid-state desolvation of purine and pyrimidine hydrates: loss of water of crystallization from thymine monohydrate, cytosine monohydrate, 5-nitrouracil monohydrate, and 2'-deoxyadenosine monohydrate. $J$. Org. Chem. 1982, 47 (24), 4671-6.

26. Arlin, J.-B.; Bhardwaj, R. M.; Johnston, A.; Miller, G. J.; Bardin, J.; MacDougall, F.; Fernandes, P.; Shankland, K.; David, W. I. F.; Florence, A. J., Structure and stability of two polymorphs of creatine and its monohydrate. CrystEngComm 2014, 16 (35), 8197-8204.

27. Bond, A. D.; Cornett, C.; Larsen, F. H.; Qu, H.; Raijada, D.; Rantanen, J., Structural basis for the transformation pathways of the sodium naproxen anhydrate-hydrate system. IUCrJ 2014, 1 (5), 328-337.

28. Braun, D. E.; Griesser, U. J., Supramolecular Organization of Nonstoichiometric Drug Hydrates: Dapsone. Front Chem 2018, 6, 31.

29. Furuta, H.; Mori, S.; Yoshihashi, Y.; Yonemochi, E.; Uekusa, H.; Sugano, K.; Terada, $\mathrm{K}$., Physicochemical and crystal structure analysis of pranlukast pseudo-polymorphs I: Anhydrates and hydrate. J. Pharm. Biomed. Anal. 2015, 107, 11-16.

30. Murphy, B. J.; Casteel, M. J.; Samas, B.; Krzyzaniak, J. F., Thermodynamic stability considerations for isostructural dehydrates. J. Pharm. Sci. 2012, 101 (4), 1486-95.

31. Stephenson, G. A.; Groleau, E. G.; Kleemann, R. L.; Xu, W.; Rigsbee, D. R., Formation of Isomorphic Desolvates: Creating a Molecular Vacuum. J. Pharm. Sci. 1998, 87 (5), 536-542.

32. Te, R. L.; Griesser, U. J.; Morris, K. R.; Byrn, S. R.; Stowell, J. G., X-ray Diffraction and Solid-State NMR Investigation of the Single-Crystal to Single-Crystal Dehydration of Thiamine Hydrochloride Monohydrate. Cryst. Growth Des. 2003, 3 (6), 997-1004.

33. Braun, D. E.; Kahlenberg, V.; Griesser, U. J., Experimental and Computational Hydrate Screening: Cytosine, 5-Flucytosine, and Their Solid Solution. Cryst. Growth Des. 2017, 17 (8), 4347-4364. 
34. Gillon, A. L.; Davey, R. J.; Storey, R.; Feeder, N.; Nichols, G.; Dent, G.; Apperley, D. C., Solid State Dehydration Processes: Mechanism of Water Loss from Crystalline Inosine Dihydrate. J. Phys. Chem. B 2005, 109 (11), 5341-5347.

35. Basford, P. A.; Back, K. R.; Cram, M.; Docherty, R.; Davey, R. J.; Cruz-Cabeza, A. J., Impact of Crystal Structure and Molecular Conformation on the Hydration Kinetics of Fluconazole. Cryst. Growth Des. 2019, 19 (12), 7193-7205.

36. Alkhamis, K. A.; Obaidat, A. A.; Nuseirat, A. F., Solid-state characterization of fluconazole. Pharm Dev Technol 2002, 7 (4), 491-503.

37. Desai, S. R.; Shaikh, M. M.; Dharwadkar, S. R., Thermoanalytical study of polymorphic transformation in Fluconazole drug. Thermochim. Acta 2003, 399 (1-2), 81-89.

38. Park, H. J.; Kim, M.-S.; Lee, S.; Kim, J.-S.; Woo, J.-S.; Park, J.-S.; Hwang, S.-J., Recrystallization of fluconazole using the supercritical antisolvent (SAS) process. Int. J. Pharm. 2007, 328 (2), 152-160.

39. Park, H. J.; Kim, M.-S.; Kim, J.-S.; Cho, W.; Park, J.; Cha, K.-H.; Kang, Y.-S.; Hwang, S.-J., Solid-state carbon NMR characterization and investigation of intrinsic dissolution behavior of fluconazole polymorphs, anhydrate forms I and II. Chem. Pharm. Bull. 2010, 58 (9), 1243-1247.

40. Karanam, M.; Dev, S.; Choudhury, A. R., New Polymorphs of Fluconazole: Results from Cocrystallization Experiments. Cryst. Growth Des. 2012, 12 (1), 240-252.

41. Gorkovenko, E. A.; Kichanov, S. E.; Kozlenko, D. P.; Belushkin, A. V.; Wasicki, J.; Nawrocik, W.; Mielcarek, J.; Dubrovinsky, L. S.; Lathe, C.; Savenko, B. N., The PressureInduced Polymorphic Transformations in Fluconazole. J. Pharm. Sci. 2015, 104 (12), 41644169 .

42. Caira, M. R.; Alkhamis, K. A.; Obaidat, R. M., Preparation and Crystal Characterization of a Polymorph, a Monohydrate, and an Ethyl Acetate Solvate of the Antifungal Fluconazole. J. Pharm. Sci. 2004, 93 (3), 601-611.

43. Alkhamis, K. A.; Salem, M. S.; Obaidat, R. M., Comparison between dehydration and desolvation kinetics of fluconazole monohydrate and fluconazole ethylacetate solvate using three different methods. J. Pharm. Sci. 2006, 95 (4), 859-70.

44. Bernstein, J.; Davis, R. E.; Shimoni, L.; Chang, N.-L., Patterns in hydrogen bonding: functionality and graph set analysis in crystals. Angew. Chem., Int. Ed. Engl. 1995, 34 (15), 1555-73.

45. Gillon, A. L.; Feeder, N.; Davey, R. J.; Storey, R., Hydration in Molecular Crystals A Cambridge Structural Database Analysis. Cryst. Growth Des. 2003, 3 (5), 663-673.

46. TRIOS, 4.3.1; TA Instruments, 159 Lukens Drive, New Castle, DE 19720, USA: 2018.

47. LINK, 1.05.8; Linkam Scientific Instruments Ltd, Unit 8, Epsom Downs Metro Centre, Tadworth, , Surrey, KT20 5LR, UK: 2016.

48. DIFFRAC.EVA, v4.2.1.10; Bruker AXS GmbH, Karlsruhe, Germany: 2016.

49. CrysAlisPro 1.171.38.43d Rigaku Oxford Diffraction: 2015.

50. Vyazovkin, S.; Burnham, A. K.; Criado, J. M.; Pérez-Maqueda, L. A.; Popescu, C.; Sbirrazzuoli, N., ICTAC Kinetics Committee recommendations for performing kinetic computations on thermal analysis data. Thermochimica Acta 2011, 520 (1), 1-19.

51. Friedman, H. L., Kinetics of thermal degradation of char-forming plastics from thermogravimetry. Application to a phenolic plastic. Journal of Polymer Science Part C: Polymer Symposia 1964, 6 (1), 183-195.

52. COMPASSSun, H., COMPASS: An ab Initio Force-Field Optimized for CondensedPhase ApplicationsOverview with Details on Alkane and Benzene Compounds. The Journal of Physical Chemistry B 1998, 102 (38), 7338-7364. 
53. Sun, H., COMPASS: An ab Initio Force-Field Optimized for Condensed-Phase ApplicationsOverview with Details on Alkane and Benzene Compounds. The Journal of Physical Chemistry B 1998, 102 (38), 7338-7364.

54. Sun, H.; Ren, P.; Fried, J. R., The COMPASS force field: parameterization and validation for phosphazenes. Computational and Theoretical Polymer Science 1998, 8 (1), 229-246.

55. Sun, H.; Jin, Z.; Yang, C.; Akkermans, R. L. C.; Robertson, S. H.; Spenley, N. A.; Miller, S.; Todd, S. M., COMPASS II: extended coverage for polymer and drug-like molecule databases. Journal of Molecular Modeling 2016, 22 (2), 47.

56. Marchese Robinson, R. L.; Geatches, D.; Morris, C.; Mackenzie, R.; Maloney, A. G. P.; Roberts, K. J.; Moldovan, A.; Chow, E.; Pencheva, K.; Vatvani, D. R. M., Evaluation of Force-Field Calculations of Lattice Energies on a Large Public Dataset, Assessment of Pharmaceutical Relevance, and Comparison to Density Functional Theory. Journal of Chemical Information and Modeling 2019, 59 (11), 4778-4792.

57. Khankari, R. K.; Law, D.; Grant, D. J. W., Determination of water content in pharmaceutical hydrates by differential scanning calorimetry. Int. J. Pharm. 1992, 82 (1-2), 117-27.

58. Orben, C. M.; Dittrich, B., Hydrogen ADPs with $\mathrm{Cu}$ K[alpha] data? Invariom and Hirshfeld atom modelling of fluconazole. Acta Crystallographica Section C 2014, 70 (6), $580-583$.

59. Zhu, H.; Grant, D. J. W., Dehydration behavior of nedocromil magnesium pentahydrate. Int. J. Pharm. 2001, 215 (1-2), 251-262.

60. Shimanovich, R.; Cooke, M.; Peterson, M. L., A rapid approach to the preliminary assessment of the physical stability of pharmaceutical hydrates. Journal of Pharmaceutical Sciences 2012, 101 (10), 4013-4017.

61. Joseph, A.; Bernardes, C. E. S.; Viana, A. S.; Piedade, M. F. M.; Minas da Piedade, M. E., Kinetics and Mechanism of the Thermal Dehydration of a Robust and Yet Metastable Hemihydrate of 4-Hydroxynicotinic Acid. Cryst. Growth Des. 2015, 15 (7), 3511-3524.

62. Dong, Z.; Salsbury, J. S.; Zhou, D.; Munson, E. J.; Schroeder, S. A.; Prakash, I.; Vyazovkin, S.; Wight, C. A.; Grant, D. J. W., Dehydration kinetics of neotame monohydrate. J. Pharm. Sci. 2002, 91 (6), 1423-1431.

63. Sheth, A. R.; Zhou, D.; Muller, F. X.; Grant, D. J. W., Dehydration kinetics of piroxicam monohydrate and relationship to lattice energy and structure. J. Pharm. Sci. 2004, 93 (12), 3013-3026.

64. Zhou, D.; Schmitt, E. A.; Zhang, G. G. Z.; Law, D.; Wight, C. A.; Vyazovkin, S.; Grant, D. J. W., Model-free treatment of the dehydration kinetics of nedocromil sodium trihydrate. J. Pharm. Sci. 2003, 92 (7), 1367-1376.

65. Davey, R. J.; Back, K. R.; Sullivan, R. A., Crystal nucleation from solutions transition states, rate determining steps and complexity. Faraday Discussions 2015, 179, 926.

66. Jia, L.; Svärd, M.; Rasmuson, Å. C., Crystal Growth of Salicylic Acid in Organic Solvents. Crystal growth \& design 2017, 17 (6), 2964-2974.

67. Kumar, K. V.; Rocha, F., Kinetics and thermodynamics of sucrose crystal growth in the presence of a non-ionic surfactant. Surface Science 2010, 604 (11), 981-987.

68. Mullin, J. W., 6 - Crystal growth. In Crystallization (Fourth Edition), Mullin, J. W., Ed. Butterworth-Heinemann: Oxford, 2001; pp 216-288.

69. Shiau, L.-D., Determination of the Nucleation and Growth Kinetics for Aqueous Lglycine Solutions from the Turbidity Induction Time Data. Crystals 2018, 8 (11), 403.

70. Soto, R.; Rasmuson, Å. C., Crystal Growth Kinetics of Piracetam Polymorphs in Ethanol and Isopropanol. Crystal growth \& design 2019, 19 (8), 4273-4286. 
71. Bomio, P.; Bourne, J. R.; Davey, R. J., The growth and dissolution of hexamethylene tetramine in aqueous solution. Journal of Crystal Growth 1975, 30 (1), 77-85. 


\section{For Table of Contents Use Only}

\section{Conformational Change Initiates Dehydration in Fluconazole Monohydrate}

Patricia A. Basford, Christopher A. Cameron and Aurora J. Cruz-Cabeza,

\section{SYNOPSIS TOC}

Conformational change has been revealed as the initiating step in the dehydration mechanism of fluconazole monohydrate. Rotational change to the hydroxyl group, as the temperature is increased, destabilises the monohydrate structure, whereby water gains enough mobility to migrate within the lattice.

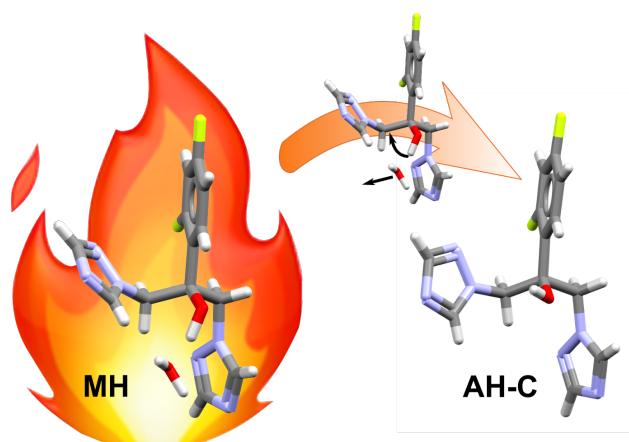

Please also use as Abstract graphic 